REVIEW

\title{
Molecular pathology of ataxia telangiectasia
}

\author{
A M R Taylor, P J Byrd
}

J Clin Pathol 2005;58:1009-1015. doi: 10.1136/icp.2005.026062

Ataxia telangiectasia (A-T) is one of a group of autosomal recessive cerebellar ataxias. Presentation is usually by the age of 2 years and ataxia of both upper and lower limbs develops, such that by early teenage most patients require a wheelchair for mobility. Speech and eye movement are also affected. Other important features are $t(7 ; 14)$ translocations, immunodeficiency, a high serum $\alpha$ fetoprotein concentration, growth retardation, telangiectasia-most noticeably on the bulbar conjunctiva-and a very high risk of developing a lymphoid tumour. Patients also show an increased sensitivity to ionising radiation. The classic form of A-T results from the presence of two truncating ATM mutations, leading to total loss of the ATM protein, a protein kinase. Importantly, A-T shows clinical heterogeneity, including milder forms where neurological progression may be slower or of later onset. In these cases there is a correlation between the preservation of neurological function, decreased radiosensitivity, and the degree of retained ATM protein kinase activity. Considerable scope remains for understanding the progress of the disorder in relation to the types of ATM mutation present.

\begin{abstract}
See end of article for authors' affiliations

Correspondence to: Professor A M R Taylor, CR-UK Institute for Cancer Studies, University of Birmingham, Vincent Drive, Edgbaston, Birmingham B15 2TT, UK;A.M.R.Taylor@bham. ac.uk
\end{abstract}

Accepted for publication 3 March 2005
A taxia telangiectasia $(\mathrm{A}-\mathrm{T})$ is inherited in an autosomal recessive manner and results in a progressive neurological disorder resulting from cerebellar degeneration. The birth frequency in the UK is approximately 1 in $300000 .^{1}$ Presentation is usually by the age of 2 years; ataxia of both upper and lower limbs develops and by early teenage most patients require a wheelchair for mobility. Speech and eye movement are also affected..$^{2-4}$ Ten measurable neurological traits have been described and shown to be similar between affected A-T siblings within families but different between families. ${ }^{2}$ The suggestion is that other genetic or environmental influences may also contribute to the variation in neurological presentation.

A-T is a complex disorder that also results in immunodeficiency. All patients probably have a deficiency of cell mediated immunity, whereas deficiency in humoral immunity is more variable. The resulting predisposition to infection is very variable between patients, with most not noticeably affected, but others showing frequent episodes of severe infection, ${ }^{5}$ and approximately $10-15 \%$ of patients require immunoglobulin replacement. The susceptibility to upper respiratory tract infection is rarely progressive and there is no susceptibility to opportunistic infections. ${ }^{5}$ In contrast, there is an increase in lower respiratory tract infections with age. ${ }^{5}$ This may be partly a consequence of the aspiration of food as a result of impaired swallowing and deficient cough reflex. ${ }^{6}$ Recurrent pulmonary infection may lead to chronic lung damage, further increasing susceptibility to new infections.

"All patients probably have a deficiency of cell mediated immunity, whereas deficiency in humoral immunity is more variable"

Patients with A-T also show thymic hypoplasia, high serum $\alpha$ fetoprotein (AFP) concentrations, growth retardation, and telangiectasia of different parts of the body, most noticeably the bulbar conjunctiva. Patients also show an increased sensitivity to ionising radiation (IR). An important feature of these patients is their very high risk of developing cancer, principally lymphoid tumours. ${ }^{78}$ Fifteen percent of patients with A-T in the UK die of a leukaemia or lymphoma as children.

There is clinical heterogeneity within the disorder ranging from the classic form with onset in infancy and steady progression of the disorder, to milder forms where progression may be slower or onset may be later. In addition, there are other neurological disorders with features similar to those of A-T. These include A-T-like disorder (ATLD), ataxia oculomotor apraxia 1 (AOAl), and AOA2 (see below).

An understanding of the function of the ATM gene is important not only for patients with A-T but also for the wider population. Approximately $0.5 \%$ of the UK population are carriers of a mutation in the ATM gene. There is evidence that female ATM mutation carriers are at a small increased risk of developing breast cancer. ${ }^{9-11}$ In addition, sporadic forms of leukaemia, occurring in the general population, have been shown to be associated with mutation of the ATM gene. ${ }^{12}$

\section{CELLULAR FUNCTIONS OF THE ATM PROTEIN}

The ATM gene is large, spanning $150 \mathrm{~kb}$ of genomic DNA, and encoding a ubiquitously expressed transcript of approximately $13 \mathrm{~kb}$, consisting of 66 exons, giving a $350 \mathrm{kDa}$ protein of 3056 amino acids. ${ }^{13}$ The ATM protein has a central role in the cellular response to DNA damage. ATM is principally a nuclear serine/

Abbreviations: AFP, $\alpha$ fetoprotein; A-T, ataxia telangiectasia; ATLD, ataxia telangiectasia-like disorder; $A O A$, ataxia oculomotor apraxia; $I R$, ionising radiation; NBS, Niimegen breakage syndrome; SCANI, spinocerebellar ataxia with axonal neuropathy 
threonine protein kinase that is activated by autophosphorylation after exposure of cells to $\mathrm{IR}^{14}$ and it has many substrates all with a general consensus motif (SQ/TQ). ${ }^{15}$ Broadly speaking, the ATM kinase is involved in the cellular response to DNA double strand breaks. As a protein kinase it is involved in transducing the signal in response to DNA damage. Normally, ATM is involved in activating the Gl-S, S, and G2-M cell cycle checkpoints after exposure to DNA damage by phosphorylation of different targets. ${ }^{13}{ }^{15} \mathrm{~A}$ deficiency in ATM leads to loss of these checkpoints and, therefore, progression of cells through the cell cycle at inappropriate times. ATM deficient cells also have a defect in stress response pathways, ${ }^{13}$ and cells defective in ATM appear to be more resistant to IR induced apoptosis, although this could be a cell type specific response. ${ }^{16}{ }^{17}$ ATM also has a role in phosphorylating proteins that are recruited to the sites of DNA double strand breaks, ${ }^{18}$ and this results in enhanced cell survival. This is believed to occur through some role in DNA repair. The details of many of these functions remain unknown. ATM is part of the BRCAl associated genome surveillance complex. ${ }^{19}$ In addition to ATM, the hMrellhRad50-Nbsl complex, and BRCAl, at least five other proteins are reported to be in this large complex. Interestingly, mutation of the hMrell component of the hMrell-hRad50-Nbsl DNA double strand break repair complex also gives rise to an A-T-like disorder (see below).

\section{THE RANGE OF MUTATIONS IN THE ATM GENE AND THEIR EFFECTS}

The classic form of A-T results from the presence of two truncating ATM mutations, leading to total loss of function of the ATM protein ${ }^{20}$ whereas milder forms are associated with a leaky splice site ATM mutation ${ }^{21-23}$ or the presence of missense mutations. ${ }^{22} 24$

\section{ATM protein truncating mutations}

The sine qua non for the diagnosis of classic A-T is the presence of both progressive cerebellar ataxia and oculocutaneous telangiectasia, ${ }^{7}$ and the classic form of A-T is caused by loss of function of the ATM protein from both alleles as a result of total absence of ATM protein..$^{20}$ This occurs mostly as a result of either compound heterozygosity or, less frequently, homozygosity for a truncating mutation(s) (frameshift or nonsense mutations) that results in failure of formation of stable ATM protein. It is from these patients that cultured cells show the greatest degree of radiosensitivity. The frequency of occurrence of biallelic truncating mutations will probably vary between populations depending on the spectrum of mutations present. Interestingly, the fact that patients with A-T can have two truncating mutations shows that $A T M$ is not an essential gene.

\section{ATM missense mutations}

The presence of a missense mutation may allow some expression of mutant ATM with a degree of residual kinase activity and this may result in a milder clinical appearance.

\section{ATM splice site mutations}

The presence of particular splice site mutations allows some normal transcript to be expressed and may also be associated with a milder clinical phenotype. ${ }^{21}{ }^{25}$

\section{ATM founder mutations}

At least 11 mutations, each identified in more than one UK family, have been confirmed as founder mutations by the presence of a common haplotype within the families. ${ }^{24}$ In all, approximately a quarter of families carried one of these founder mutations.

\section{New ATM mutations}

New ATM mutations occur rarely in patients with A-T and we are aware of one such patient where the patient inherited the maternal ATM mutation, 4588G $>$ T (E1530X). The second mutation 8189A $>$ C (Q2730P) was present in neither parent although haplotyping established paternity. It could be shown that the two sequence changes were not in the same allele, ruling out a spontaneously occurring maternal sequence change. The most likely explanation was a de novo mutation during male meiosis.

\section{GENOTYPE-PHENOTYPE CORRELATIONS IN A-T}

Although the classic A-T phenotype arises as a result of loss of function of both ATM alleles, the clinical presentation is recognisably milder in the presence of particular mutation types.

Where there is expression of a low amount of normal ATM protein in cells with an ATM splicing mutation An important ATM mutation found in approximately $10 \%$ of all patients with A-T in the UK is ATM 5762 ins 137 (resulting from mutation IVS40 $+1126 \mathrm{~A}>\mathrm{G}$ ). Most of these patients are compound heterozygotes for the 5762ins 137 mutation in one allele and a truncating mutation in the second allele. This particular insertion results from a single $A>G$ point mutation, which creates a splice donor signal that preferentially splices to the $3^{\prime}$ exon, which then forces the $5^{\prime}$ exon to splice to a cryptic splice acceptor site in the intron, resulting in a $137 \mathrm{bp}$ intronic insert being spliced into the ATM transcript. The $137 \mathrm{bp}$ insertion is predicted to result in a truncated protein, but instability of this truncated protein means that it is rapidly degraded. ${ }^{21}$ However, some protein expression is seen and this comes from the mutated allele as a result of the leakiness of the mutation; splicing principally involves the splice donor site created in the intron, but a small number of correctly spliced ATM transcripts are produced from which normal protein is expressed. Cells from patients heterozygous for the 5762 ins 137 mutation are estimated to express $4 \%$ of the normal amount of ATM protein..$^{22}$ The presence of the 5762ins 137 mutation in the heterozygous state delays slightly the onset of the cerebellar ataxia but more significantly affects the rate of progress of the cerebellar degeneration.

\section{"Although $50 \%$ of normal ATM protein values, as seen in heterozygotes, prevents ataxia telangiectasia $(A-T)$, it is not known what threshold value of ATM kinase activity is required to prevent the development of $A-T^{\prime \prime}$}

The presence of 5762ins 137 has also been described in the homozygous state. ${ }^{23}$ In this case, the A-T had adult onset. This contrasts with the usual age of less than 2 years when cerebellar ataxia is noted. Cells from patients homozygous for the mutation produce $\sim 10 \%$ of the normal amount of ATM protein. The cells of these patients have an inducible kinase activity three to four times that of cells from patients with A$\mathrm{T}$ who are heterozygous for the 5762 ins 137 mutation, and about $10 \%$ of that seen in normal cells. In summary, it appears that $\sim 10 \%$ of normal ATM kinase activity is sufficient to moderate the phenotype but not to prevent it. Although $50 \%$ of normal ATM protein values, as seen in heterozygotes, prevents A-T, it is not known what threshold value of ATM kinase activity is required to prevent the development of A-T.

Gilad et al described two patients with A-T homozygous for another "leaky" splice site mutation (3576G>A) leading to loss of exon 26 (3403dell74). ${ }^{26}$ Cells from both patients expressed a low amount $(\sim 5 \%)$ of full length and presumably normal ATM protein, although ATM kinase activity assays were not reported. The patients were longer 
lived although onset was during infancy. Assuming that the ATM is in fact normal, these patients might be expected to be similar to the 5762 ins 137 compound heterozygotes in terms of severity of the disorder although it was suggested that the rate of progression of $\mathrm{A}-\mathrm{T}$ in the $3576 \mathrm{G}>\mathrm{A}$ patients was classic.

\section{Where there is expression of mutant ATM protein in cells with ATM missense mutations}

Not all ATM missense mutations result in expression of stable ATM protein and where stable ATM is expressed kinase activity may be absent; this is the case for the new mutation 8189A $>$ C (Q2730P) (described above), which allows the expression of almost normal amounts of ATM that has no kinase activity. Homozygosity for the ATM missense mutation 7875T $>$ G/7876G $>$ C $(\text { D2625E/A2626P })^{27}$ has been reported in siblings who were apparently classic A-T cases. There was no indication of whether ATM protein was expressed in cells from these patients. In a patient homozygous for the 9022C > T (R3008C) mutation total absence of ATM kinase activity was reported, ${ }^{28}$ although the amount of ATM protein expressed was about half that of normal cells.

However, there are some rare examples of ATM missense mutations where expression of mutant protein has resulted in milder clinical and cellular phenotypes. An example of this is the 7271T $>\mathrm{G}$ (V2424G) mutation seen in three families in the UK. ${ }^{24}$ In two of the families the mutation is present in one allele. Mutant protein is expressed from this allele and it has some residual kinase activity. ${ }^{22}$ This is consistent with the milder clinical picture. The mutation has also been described in the homozygous state in a family where A-T was milder still. ${ }^{24}$ Although first noted in early childhood, the progression of the cerebellar ataxia was slow and three siblings, aged 62 years, 51 years, and 49 years and homozygous for the mutation, retained the ability to walk, with help.

Dork and colleagues ${ }^{29}$ described a patient with A-T who survived until age 60 years with a double missense mutation $(7875 \mathrm{~T}>\mathrm{G} / 7876 \mathrm{G}>\mathrm{C}$ ) (the same mutation as described by van Belzen et al) $)^{27}$ in one allele and a splice site mutation (IVS7 +5G>A) in the second allele. Some residual ATM kinase activity was demonstrable but it was uncertain whether one or both alleles contributed to this. Apart from the patients with the V2424G mutation, there is no other clear example of patients with A-T with a milder clinical picture, either homozygous or compound heterozygous for other pathogenic missense mutations.

\section{OTHER DISORDERS WITH FEATURES OF A-T}

$\mathrm{A}-\mathrm{T}$ is one of a group of recessive neurological disorders where cerebellar ataxia is a predominant feature. At the clinical level the differential diagnosis of A-T in young children can be difficult. Apart from Friedreich's ataxia there are several other disorders with neurological features similar to A-T. These include the rare ATLD (OMIM 604391) ${ }^{30}$ with mutation of the MRE11 gene, and the more common disorder, AOAl. ${ }^{31}$ The APTXI gene (OMIM 606350), mutated in AOAl, has been sequenced and mutations originally described in the Japanese and Portuguese populations. ${ }^{32}{ }^{33}$ The protein encoded by the APTXI gene has been named aprataxin. A further recessive ataxia AOA2 has been described that maps to chromosome $9 \mathrm{q} 34 .^{34}$ Another disorder termed spinocerebellar ataxia with axonal neuropathy (SCANl; OMIM 607250 ) was recently described, caused by mutation in the TDPl gene. ${ }^{35}$

\section{Ataxia telangiectasia-like disorder}

Mutation in a second gene, $h M R E 11$, can result in the clinical features of A-T without telangiectasia or raised serum AFP. ${ }^{30}{ }^{36-40}$ ATLD is difficult to distinguish neurologically from A-T and accounts for only a small proportion of patients with A-T. These patients also show the increased radiosensitivity seen in A-T. The fact that mutation of hMRE1l, a second member of the hMrell-hRad50-Nbsl protein complex, leads to both the clinical and cellular phenotypes of A-T, provides compelling evidence that this complex acts in the same pathway as the ATM gene. The data show that ATM and members of the hMrell-hRad50-Nbsl protein complex are not functionally redundant. It would be interesting to know what the clinical appearance of a patient with ATLD and two missense mutations might be. Very recently, 10 Saudi families with ATLD, all homozygous for the same hMRE11 missense mutation $\left(630 \mathrm{G}>\mathrm{C}\right.$, W210C) were reported. ${ }^{40}$ Although these patients also presented with early onset and progressive ataxia together with abnormal eye movement, interestingly, some patients in two of the families also showed microcephaly. In contrast to previous patients, cell lines from two of these expressed normal amounts of hMrell and hRad50 but greatly reduced amounts of Nbs l, rendering the MRN complex unstable.

\section{Nijmegen breakage syndrome}

For some time A-T was the only disorder in which increased radiosensitivity was a recognised part of the syndrome. Subsequently, patients were described with the Nijmegen breakage syndrome (NBS), ${ }^{41}$ caused by mutation of the NBSI gene $^{42}{ }^{43}$ (which encodes a member of the hMrell-hRad50Nbsl complex) who also show increased radiosensitivity. ${ }^{44}$ These two disorders show similar features at the cellular level, based mainly on their increased sensitivity to IR. This observation led to the suggestion that the genes causing the two disorders were probably involved in the same damage response pathway. ${ }^{45-48}$ Clinical overlap, however, between A-T and NBS is only partial. This includes immunodeficiency and increased risk of lymphoid malignancies, although B cell tumours predominate in patients with NBS. ${ }^{41}$ Patients with NBS show microcephaly and frequently borderline mental retardation but do not develop cerebellar degeneration or telangiectasia. They also show chromosome translocations in peripheral lymphocytes with breaks at the sites of the $\mathrm{T}$ cell receptor genes.

Recently, a patient diagnosed with atypical Fanconi anaemia was shown to be homozygous for an NBSI mutation and to show total cellular loss of the Nbsl protein. ${ }^{49}$ This indicates some possible overlap of clinical features between NBS and Fanconi anaemia in rare instances. Both NBS and ATLD cells were also shown to be unusually sensitive to DNA crosslinking agents, showing that at the cellular level there are common features between NBS, ATLD, and Fanconi anaemia. $^{49}$

\section{Deficiency in hRad50}

hRad50 is the third component of the Mrell-Rad50-Nbsl complex in mammalian cells. Because two of these proteins, hMrell and Nbsl, are defective in ATLD and NBS, respectively, it is very likely that mutation will be reported in the hRad50 gene in due course.

\section{Ataxia oculomotor apraxia 1}

Neurologically, these patients are almost identical to patients with A-T, although they do not show the non-neurological features, such as immunodeficiency, raised concentrations of serum AFP, abnormal chromosome translocations in the peripheral blood, or cancer predisposition. ${ }^{31}$ Little is known about the frequency of AOAl in the UK. AOAl is first recognised by about 5 years of age, later than A-T, and most patients are wheelchair bound by early adulthood. It is caused by mutation of the APTXI gene. ${ }^{32}{ }^{33}$ The protein expressed from APTX1, aprataxin, is a member of the HIT domain superfamily of nucleotide hydrolases/transferases 
and may be linked to DNA single and double strand break repair. $^{51-53}$

\section{Ataxia oculomotor apraxia 2}

The mean age of onset of the cerebellar ataxia is about 15 years and the disorder may be as frequent as AOAl and A-T. ${ }^{54}$ Interestingly, like A-T, patients show raised concentrations of serum AFP. ${ }^{55}{ }^{56}$ Recently, the AOA2 gene (OMIM 606002) has been identified and sequenced, ${ }^{54}$ and the protein termed senataxin. Senataxin may have both RNA and DNA helicase activities, and like some of the other proteins associated with these cerebellar disorders may have functions in DNA repair. ${ }^{57}$

\section{Spinocerebellar ataxia with axonal neuropathy}

SCANI (OMIM 607250) is extremely rare and was originally described in a Saudi family..$^{35}$ SCAN1 is caused by mutation of the DNA repair protein tyrosyl DNA phosphodiesterase 1 (the TDPI gene). Onset is during the teenage years with both moderate ataxia and mild dysarthria developing but without abnormal eye movement.

\section{LABORATORY CONFIRMATION OF THE CLINICAL DIAGNOSIS OF A-T AND OTHER A-T TYPE DISORDERS}

The diagnosis of A-T can be confirmed by identification of both ATM mutations. In practice, the size of the ATM coding sequence and the absence of common mutations can make this a lengthy and sometimes uncertain procedure. In contrast, the presence of increased chromosomal radiosensitivity can be established quickly as can the total absence (in most cases) or the greatly reduced expression of the ATM protein in a lymphoblastoid cell line made from the patient's lymphocytes (fig 1). Finally, the kinase activity of any residual ATM protein can be assayed in cases where an unusual presentation is $\operatorname{seen}^{22} 23$ (fig 2).

Therefore, laboratory confirmation of the clinical diagnosis of the classic form of A-T is relatively straightforward. Such

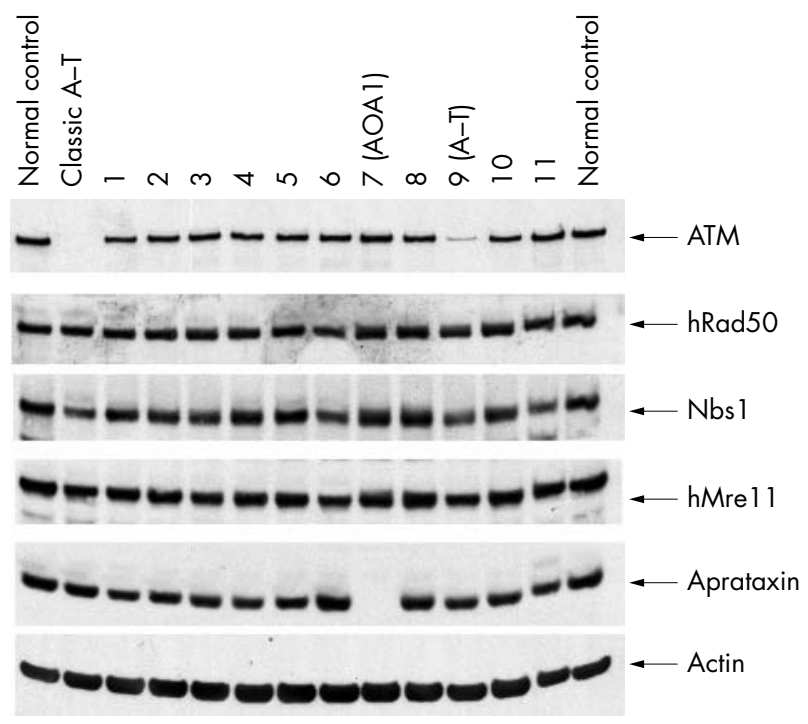

Figure 1 An aid to the confirmation of ataxia telangiectasia (A-T) or ataxia oculomotor apraxia 1 (AOA1) by screening for the loss of a DNA damage response protein. Lymphoblastoid cell lines were derived from blood samples of 11 consecutive patients and screened for ATM, hRad50, Nbs 1, hMre 1 1, and aprataxin by western blotting. Actin was used as the loading control. The western blot shows that cell extracts from two of the patients are abnormal; patient 7 has no aprataxin and patient 9 has a very much reduced amount of ATM protein. After this initial screen, mutations for APTX1 and ATM, respectively, were identified.

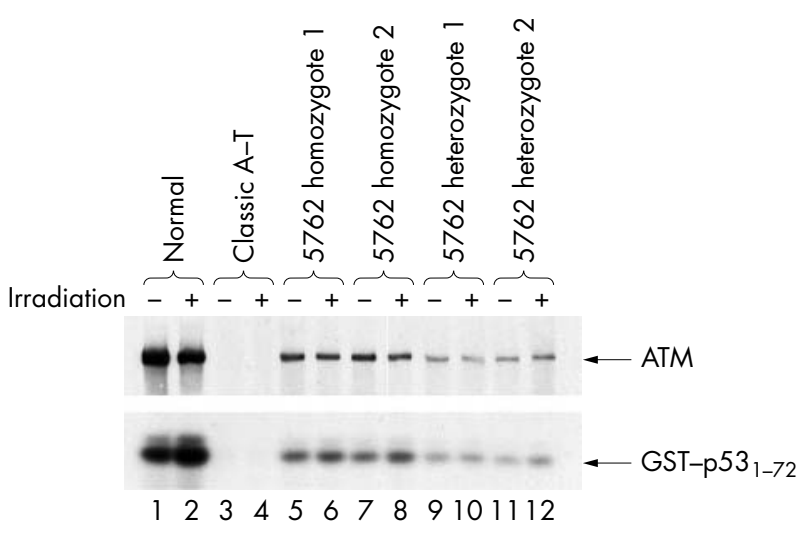

Figure 2 Cells from patients with ataxia telangiectasia (A-T) and a milder clinical presentation retain some ATM kinase activity. An in vitro assay of $\gamma$ ray induced ATM activity shows that cells derived from patients with A-T and either one or both ATM alleles carrying the 5762 ins 137 mutation retain some ATM kinase activity. Cells

homozygous (lanes 6 and 8) for the mutation show approximately three times the induced activity of heterozygous cells (lanes 10 and 12). The induced ATM kinase activity in a normal cell extract is shown in lane 2 and absence of activity in extracts of cells from a patient with classic A-T in lane 4. ATM was immunoprecipitated from $2 \mathrm{mg}$ of protein of the cell extract in each lane, except for the normal control, where only 1 mg was used. The ATM was then used to phosphorylate a $\mathrm{p} 53_{1-72}$ substrate (bottom panel). The relative amounts of ATM used in the kinase assay are shown in the top panel. Taken from Sutton et al. ${ }^{23}$

patients usually present with neurological symptoms, show greatly increased chromosomal radiosensitivity, the presence of translocations involving chromosomes 7 and 14, and total absence of the ATM protein. At the gene level, biallelic truncating mutations will provide the final confirmation of the diagnosis. Where A-T is suspected but may not be of the classic form, this combination of assays will again provide data to confirm or refute this possibility. In very rare cases where there are two ATM missense mutations present that may be construed as ATM polymorphisms, possibly resulting in a "normal amount" of ATM protein, the kinase assay will provide a means of determining whether ATM kinase activity is abnormal.

"Laboratory confirmation of the clinical diagnosis of the classic form of ataxia telangiectasia is relatively straightforward"

Patients with the neurological features of A-T and the presence of radiosensitivity in whom the ATM protein is also present and ATM mutations cannot be identified may have ATLD (with mutations of the $h M R E 11$ gene). In patients with ATLD, the expression of Nbsl and hRad50 may be affected in addition to hMrell.

If there are neurological features of $\mathrm{A}-\mathrm{T}$, but there are normal amounts of ATM, the hMrell complex proteins are present, and there is no increased radiosensitivity, then either AOAl or AOA2 is a possibility. The diagnosis of AOAl can be made by both DNA sequencing for the presence of a mutation and detecting loss of the aprataxin protein (the protein lost in $\mathrm{AOAl}$ ) (fig 1). Although the AOA2 gene is much larger than the AOAl gene, DNA can be screened for mutations, but at present there is no antibody to detect loss of the senataxin protein.

\section{MUTATION OF ATM AND MALIGNANT DISEASE IN} PATIENTS WITH A-T

An increased risk of developing malignant disease is an important feature of A-T. Approximately $10-15 \%$ of all 
patients with A-T develop malignancy in childhood, with most tumours being lymphoid in origin, such as B cell nonHodgkin lymphoma, $\mathrm{T}$ cell lymphoid tumours ( $\mathrm{T}$ cell lymphoma and $\mathrm{T}$ cell acute lymphoblastic leukaemia), and Hodgkin disease. Indeed, it is possible that the diagnosis offor example, $\mathrm{T}$ cell acute lymphoblastic leukaemia-may precede the diagnosis of A-T. A pre-existing large clone in the peripheral blood lymphocytes of patients with A-T is associated with a high risk of developing $\mathrm{T}$ cell prolymphocytic leukaemia. ${ }^{8}$ The presence of chromosomal translocations involving immune system genes and oncogenes may explain the potential for the development of several forms of lymphoid tumours in patients with A-T. Other tumours, including brain tumours and certain carcinomas, are also seen in patients with A-T. ${ }^{24} 58$

\section{CANCER RISKS OF ATM MUTATION CARRIERS IN A- T FAMILIES}

Although ATM mutations in patients with A-T predispose to lymphoid tumours the effect of the mutations may be numerically more important in the heterozygous state. ATM mutation carriers have been reported to have an increased risk of breast cancer. In a prospective study, ${ }^{9}$ it was estimated that women in families affected by A-T who were heterozygous for the A-T gene were 5.5 times $(95 \%$ confidence interval, 1.5-16.9) more likely to develop breast cancer than non-carriers of an ATM mutation. In a meta-analysis of different studies, Easton ${ }^{59}$ estimated that the relative risk of breast cancer in A-T heterozygotes was 3.9 fold. More recent studies have tended to confirm this small increased risk for carriers in families affected by A-T. ${ }^{10}{ }^{11}$ There is also the possibility that the risk may be higher for certain mutations, including missense mutations expressing abnormal ATM protein, and therefore involvement of ATM gene mutations in breast cancer may be important in particular families.

\section{ATM MUTATION IN FAMILIAL BREAST CANCER AND SPORADIC TUMOURS}

The contribution of ATM mutations to breast cancer is currently not known. Germline ATM mutations were found to be present in only two of 401 women with early onset breast cancer compared with two of 202 controls. $^{60}$ It was concluded that heterozygous mutations do not confer genetic predisposition to early onset breast cancer. However, the results of that study are consistent with a moderate risk of breast cancer because the confidence interval was large ${ }^{61}$ In addition, the authors used a method that only detected truncated ATM protein. The role of the ATM IVS10-6T $>$ G and ATM 7271T $>$ G mutations was investigated in 961 families with non-BRCA1/BRCA2 breast cancer. ${ }^{62}$ The authors concluded that ATM 7271T $>\mathrm{G}$ is a rare event in familial breast cancer and found that the ATM IVS10-6T $>$ G mutation did not confer a significantly increased risk of breast cancer. There is no evidence that ATM mutations confer a high risk of breast cancer. ${ }^{62}$

ATM mutations play a role in the development of some sporadic lymphoid tumours. ATM mutations have been described in sporadic $\mathrm{T}$ cell prolymphocytic leukaemia, ${ }^{63-65} \mathrm{~B}$ cell chronic lymphocytic leukaemia, ${ }^{66-68}$ and mantle cell lymphoma. ${ }^{69}$

\section{DISCUSSION}

Among the group of paediatric patients with recessive cerebellar ataxia, a clinical diagnosis of classic A-T can be readily confirmed in the laboratory, enabling the distinction from other recessive forms of cerebellar ataxia such as ATLD (caused by mutation of the hMRE11 gene), AOAl, and AOA2.
"Other cases may be milder, as shown by a slightly later age of onset and slower rate of progress, as a result of the expression of some normal ATM protein from a leaky splice site mutation"

In A-T in particular, there is good evidence for true clinical heterogeneity. This can be seen as a slower rate of progress of cerebellar degeneration after onset in early childhood. These cases appear to result from the presence of one of two types of mutation. First, the presence of at least one missense mutation that is responsible for the expression of mutant ATM protein with some measurable kinase activity may contribute to the milder features. Several missense mutations have been described. Other cases of A-T may be milder, as shown by a slightly later age of onset and slower rate of progress, as a result of the expression of some normal ATM protein from a leaky splice site mutation. In rare cases genuine adult onset of A-T is seen. This can be the result of homozygosity for the 5762 ins 137 mutation. ${ }^{23}$ Apparent adult onset caused by the presence of a missense mutation has been described, although kinase activity was not obvious. ${ }^{70}$ There has been no clear description of a patient with A-T with different missense mutations in each ATM allele. It is not clear what the clinical appearance might be of such a patient. It would be interesting to examine appropriate undiagnosed adult onset neurological disorders for the possible presence of ATM mutations. There is no correlation between the amount of ATM protein and radiosensitivity (survival or radioresistant DNA synthesis). However, the results of various studies suggest that there is a clear correlation between the preservation of neurological function, decreased radiosensitivity, and the level of normal ATM protein kinase activity. Although some attempt has been made to relate the progress of the disorder to the type of mutation present, ${ }^{71}$ considerable scope remains for improving this. The notion that modifying genes may influence the A-T phenotype has been suggested, ${ }^{2}$ but investigations of the nature of these genes have not begun.

\section{Take home messages}

- Ataxia telangiectasia (A-T) is a form of autosomal recessive cerebellar ataxia that usually presents by 2 years of age, with ataxia of both upper and lower limbs developing, so that by early teenage most patients require a wheelchair for mobility

- Speech and eye movement are also affected

- It is associated with immunodeficiency, growth retardation, telangiectasia (most noticeably on the bulbar conjunctiva), a high risk of lymphoid tumours, and increased sensitivity to ionising radiation

- Classic A-T results from the presence of two truncating ATM mutations, leading to total loss of the protein kinase ATM protein

- This disease shows clinical heterogeneity, and neurological progression may be slower or of later onset in the milder forms

- The preservation of neurological function correlates with the degree of radiosensitivity and retained ATM protein kinase activity

- A-T needs to be distinguished from other neurological disorders with similar features, including A-T-like disorder (ATLD), ataxia oculomotor apraxia 1 (AOA1), and AOA2 
Interestingly, two publications analysing magnetic resonance imaging brain scans of patients with A-T have drawn attention to the observation that the relation between the degree of cerebellar atrophy and its affect on the patient's ability to walk is unclear. ${ }^{23} 72$ The relative absence of disability in a patient with A-T who was homozygous for 5762ins 137 occurred despite a moderate degree of cerebellar hemisphere atrophy and severe atrophy of the cerebellar vermis being seen on magnetic resonance imaging. ${ }^{23}$ This may be because although the cerebellum is almost universally affected in A-T, other systems such as the basal ganglia, anterior horn cells, dorsal columns, and peripheral nerves can be affected by the disease process to differing degrees, which may also affect the ability to walk. ${ }^{23} 72$

The mechanism by which the ATM protein normally protects against neurodegeneration in post-mitotic neurones is not known. The cell cycle checkpoint control associated with ATM is not likely to have much effect in post-mitotic neurones, leaving either a function of DNA repair or apoptosis of damaged neurones as the possible mechanism. The observation of a similar neurological phenotype in patients with mutations in the known DNA repair protein hMrell, suggests that impaired DNA repair mechanisms may contribute to the development of neurological dysfunction, as appears to be the case in mice that are null for the repair genes DNA ligase $\mathrm{IV}^{73}$ and $\operatorname{xrcc} 4 .^{74}$ This does not rule out a function for ATM dependent apoptosis. ${ }^{75}$

"The mechanism by which the ATM protein normally protects against neurodegeneration in post-mitotic neurones is not known"

The similarity in neurological features between A-T and AOAl is striking, and in the future we hope to understand how different pathways involving these two proteins intersect to produce the characteristic neurological features. Although the neurological changes and other risks accompanying the progression of classic A-T are known, less is clear about prognosis in the different recognisable subgroups of A$\mathrm{T}$ : those with a less severe presentation and slower rate of progress. There is still much to be learnt from carefully documenting such cases and considering the possibility that some unexplained adult onset cerebellar ataxias may be caused by mutation of the ATM gene.

\section{ACKNOWLEDGEMENTS}

We thank CR-UK, the Kay Kendall Leukaemia Fund, the Leukaemia Research Fund, and the Ataxia Telangiectasia Society for continued support.

\section{Authors' affiliations}

A M R Taylor, P J Byrd, CR-UK Institute for Cancer Studies, University of Birmingham, Vincent Drive, Edgbaston, Birmingham B15 2TT, UK

\section{REFERENCES}

1 Woods CG, Bundey SE, Taylor AM. Unusual features in the inheritance of ataxia telangiectasia. Hum Genet 1990;84:555-62.

2 Crawford TO, Mandir AS, Lefton-Greif MA, et al. Quantitative neurologic assessment of ataxia-telangiectasia. Neurology 2000;54:1505-9.

3 Farr AK, Shalev B, Crawford TO, et al. Ocular manifestations of ataxiatelangiectasia. Am J Ophthalmol 2002;134:891-6.

4 Lewis RF, Crawford TO. Slow target-directed eye movements in ataxiatelangiectasia. Invest Ophthalmol Vis Sci 2002;43:686-91.

5 Nowak-Wegrzyn A, Crawford TO, Winkelstein JA, et al. Immunodeficiency and infections in ataxia-telangiectasia. J Pediatr 2004;144:505-1 1.

6 Lefton-Greif MA, Crawford TO, Winkelstein JA, et al. Oropharyngeal dysphagia and aspiration in patients with ataxia-telangiectasia. J Pediatr 2000;136:225-31.

7 Sedgwick RP, Boder E. Ataxia telangiectasia. In: de Jong JBMV, eds. Handbook of clinical neurology. Hereditary neuropathies and spinocerebellar atrophies. Amsterdam: Elsevier Science Publishers BV, 1991:347-42.
8 Taylor AM, Metcalfe JA, Thick J, et al. Leukemia and lymphoma in ataxia telangiectasia. Blood 1996;87:423-38

9 Swift M, Morrell D, Massey RB, et al. Incidence of cancer in 161 families affected by ataxia-telangiectasia. N Engl J Med 1991;325:1831-6.

10 Olsen JH, Hahnemann JM, Borresen-Dale AL, et al. Cancer in patients with ataxia-telangiectasia and in their relatives in the Nordic countries. I Natl Cancer Inst 2001;93:121-7.

11 Geoffroy-Perez B, Janin N, Ossian K, et al. Variation in breast cancer risk of heterozygotes for ataxia-telangiectasia according to environmental factors. Int J Cancer 2002;99:619-23.

12 Stankovic T, Stewart GS, Byrd P, et al. ATM mutations in sporadic lymphoid tumours. Leuk Lymphoma 2002;43:1563-71.

13 Shiloh Y. ATM and related protein kinases: safeguarding genome integrity. Nat Rev Cancer 2003:3:155-68.

14 Bakkenist CJ, Kastan MB. DNA damage activates ATM through intermolecular autophosphorylation and dimer association. Nature 2003;421:499-506

15 Kastan MB, Lim DS. The many substrates and functions of ATM. Nat Rev Mol Cell Biol 2000;1:179-86.

16 Westphal CH, Rowan S, Schmaltz C, et al. ATM and p53 cooperate in apoptosis and suppression of tumorigenesis, but not in resistance to acute radiation toxicity. Nat Genet 1997; 16:397-401.

17 Barlow C, Brown KD, Deng CX, et al. Atm selectively regulates distinct p53dependent cell-cycle checkpoint and apoptotic pathways. Nat Genet 1997;17:453-6, Erratum in: Nat Genet 1998;18:298.

18 Kitagawa R, Bakkenist CJ, McKinnon PJ, et al. Phosphorylation of SMC1 is a critical downstream event in the ATM-NBS1-BRCA1 pathway. Genes Dev 2004; 18:1423-38.

19 Wang Y, Cortez D, Yazdi P, et al. BASC, a super complex of BRCA1associated proteins involved in the recognition and repair of aberrant DNA structures. Genes Dev 2000;14:927-39.

20 Gilad S, Khosravi R, Shkedy D, et al. Predominance of null mutations in ataxia-telangiectasia. Hum Mol Genet 1996:5:433-9.

21 McConville CM, Stankovic T, Byrd PJ, et al. Mutations associated with variant phenotypes in ataxia-telangiectasia. Am J Hum Genet 1996;59:320-30.

22 Stewart GS, Last JI, Stankovic T, et al. Residual ataxia telangiectasia mutated protein function in cells from ataxia telangiectasia patients, with 5762ins 137 and 7271T-->G mutations, showing a less severe phenotype. J Biol Chem 2001;276:30133-41.

23 Sutton IJ, Last JI, Ritchie SJ, et al. Adult-onset ataxia telangiectasia due to ATM 5762ins 137 mutation homozygosity. Ann Neurol 2004:55:891-5.

24 Stankovic T, Kidd AM, Sutcliffe A, et al. ATM mutations and phenotypes in ataxia-telangiectasia families in the British Isles: expression of mutant ATM and the risk of leukemia, lymphoma, and breast cancer. Am J Hum Genet 1998;62:334-45

25 Teraoka SN, Telatar M, Becker-Catania S, et al. Splicing defects in the ataxiatelangiectasia gene, ATM: underlying mutations and consequences. Am J Hum Genet 1999;64:1617-31.

26 Gilad S, Chessa L, Khosravi R, et al. Genotype phenotype relationships in ataxia telangiectasia and variants. Am J Hum Genet 1998;62:551-61.

27 van Belzen MJ, Hiel JA, Weemaes $C M$, et al. A double missense mutation in the ATM gene of a Dutch family with ataxia telangiectasia. Hum Genet 1998; 102:187-91

28 Angele S, Lauge A, Fernet $M$, et al. Phenotypic cellular characterization of an ataxia telangiectasia patient carrying a causal homozygous missense mutation. Hum Mutat 2003;21:169-70.

29 Dork T, Bendix-Waltes R, Wegner R-D, et al. Slow progression of ataxia telangiectasia with double missense and in frame splice mutations. Am J Med Genet 2004; 126A:272-7.

30 Stewart GS, Maser RS, Stankovic T, et al. The DNA double-strand break repair gene hMRE 11 is mutated in individuals with an ataxia-telangiectasialike disorder. Cell 1999;99:577-87.

31 Aicardi J, Barbosa C, Andermann E, et al. Ataxia-ocular motor apraxia: a syndrome mimicking ataxia-telangiectasia. Ann Neurol 1988;24:497-502.

32 Date H, Onodera O, Tanaka H, et al. Early-onset ataxia with ocular motor apraxia and hypoalbuminemia is caused by mutations in a new HIT superfamily gene. Nat Genet $2001 ; 29: 184-8$.

33 Moreira MC, Barbot C, Tachi N, et al. The gene mutated in ataxia-ocular apraxia 1 encodes the new HIT/Zn-finger protein aprataxin. Nat Genet 2001;29:189-93.

34 Nemeth AH, Bochukova E, Dunne E, et al. Autosomal recessive cerebellar ataxia with oculomotor apraxia (ataxia-telangiectasia-like syndrome) is linked to chromosome 9q34. Am J Hum Genet 2000;67:1320-6.

35 Takashima H, Boerkoel CF, John J, et al. Mutation of TDP1, encoding a topoisomerase I-dependent DNA damage repair enzyme, in spinocerebellar ataxia with axonal neuropathy. Nat Genet 2002;32:267-72.

36 Hernandez D, McConville CM, Stacey M, et al. A family showing no evidence of linkage between the ataxia telangiectasia gene and chromosome 11q2223. J Med Genet 1993;30:135-40.

37 Klein C, Wenning GK, Quinn NP, et al. Ataxia without telangiectasia masquerading as benign hereditary chorea. Mov Disord 1996;11:217-20.

38 Pitts SA, Kullar HS, Stankovic T, et al. hMRE1 1: genomic structure and a null mutation identified in a transcript protected from nonsense-mediated mRNA decay. Hum Mol Genet 2001;10:1155-62.

39 Delia D, Piane M, Buscemi G, et al. MRE 1 mutations and impaired ATMdependent responses in an Italian family with ataxia-telangiectasia-like disorder. Hum Mol Genet 2004;13:2155-63.

40 Fernet M, Gribaa M, Salih MA, et al. Identification and functional consequences of a novel MRE 11 mutation affecting ten Saudi Arabian patients with the ataxia telangiectasia-like disorder (ATLD). Hum Mol Genet 2005; 14:307-18. 
41 International Niimegen Breakage Study Group. Niimegen breakage syndrome. The international Nijmegen breakage syndrome study group. Arch Dis Child 2000;82:400-6.

42 Varon R, Vissinga C, Platzer $M$, et al. Nibrin, a novel DNA double-strand break repair protein, is mutated in Niimegen breakage syndrome. Cell 1998;93:467-76

43 Carney JP, Maser RS, Olivares H, et al. The hMre 1 1/ hRad50 protein complex and Nijmegen breakage syndrome: linkage of double-strand break repair to the cellular DNA damage response. Cell 1998;93:477-86.

44 Taalman RD, Jaspers NG, Scheres JM, et al. Hypersensitivity to ionizing radiation, in vitro, in a new chromosomal breakage disorder, the Nijmegen breakage syndrome. Mutat Res 1983;112:23-32.

$45 \mathrm{Lim}$ DS, Kim ST, Xu B, et al. ATM phosphorylates $\mathrm{p} 95 / \mathrm{nbs} 1$ in an S-phase checkpoint pathway. Nature 2000:404:613-17

46 Zhao S, Weng YC, Yuan SS, et al. Functional link between ataxiatelangiectasia and Nijmegen breakage syndrome gene products. Nature 2000;405:473-7.

47 Wu X, Ranganathan V, Weisman DS, et al. ATM phosphorylation of Nijmegen breakage syndrome protein is required in a DNA damage response. Nature 2000;405:477-82.

48 Gatei M, Young D, Cerosaletti KM, et al. ATM-dependent phosphorylation of nibrin in response to radiation exposure. Nat Genet 2000;25:115-19.

49 Nakanishi K, Taniguchi T, Ranganathan V, et al. Interaction of FANCD2 and NBS1 in the DNA damage response. Nat Cell Biol 2002:4:913-20.

50 Le Ber I, Moreira MC, Rivaud-Pechoux S, et al. Cerebellar ataxia with oculomotor apraxia type 1: clinical and genetic studies. Brain 2003;126:2761-72.

51 Caldecott KW. DNA single-strand break repair and spinocerebellar ataxia. Cell 2003;112:7-10.

52 Clements PM, Breslin C, Deeks ED, et al. The ataxia-oculomotor apraxia 1 gene product has a role distinct from ATM and interacts with the DNA strand break repair proteins XRCC1 and XRCC4. DNA Repair (Amst) 2004; 3: 1493-502.

53 Gueven N, Becherel OJ, Kijas AW, et al. Aprataxin, a novel protein that protects against genotoxic stress. Hum Mol Genet 2004;13:1081-93.

54 Le Ber I, Bouslam N, Rivaud-Pechoux S, et al. Frequency and phenotypic spectrum of ataxia with oculomotor apraxia 2: a clinical and genetic study in 18 patients. Brain 2004;127:759-67.

55 Watanabe $M$, Sugai $Y$, Concannon $P$, et al. Familial spinocerebellar ataxia with cerebellar atrophy, peripheral neuropathy, and elevated level of serum creatine kinase, gamma-globulin, and alpha-fetoprotein. Ann Neurol 1998;44:265-9.

56 Izatt L, Nemeth AH, Meesaq A, et al. Autosomal recessive spinocerebellar ataxia and peripheral neuropathy with raised alpha-fetoprotein. J Neurol 2004;251:805-12.

57 Moreira MC, Klur S, Watanabe M, et al. Senataxin, the ortholog of a yeast RNA helicase, is mutant in ataxia-ocular apraxia 2. Nat Genet 2004:36:225-7.
58 Spector BD, Filipovich AM, Perry GS, et al. Epidemiology of cancer in ataxia telangiectasia. In: Bridges BA, Harnden DG, eds. Ataxia telangiectasia-a cellular and molecular link between cancer, neuropathology and immune deficiency. Chichester: John Wiley, 1982:102-38.

59 Easton DF. Cancer risks in A-T heterozygotes. Int J Radiat Biol 1994;66:S177-82

60 FitzGerald MG, Bean JM, Hegde SR, et al. Heterozygous ATM mutations do not contribute to early onset of breast cancer. Nat Genet 1997:15:307-10.

61 Bishop DT, Hopper J. AT-tributable risks? Nat Genet 1997;15:276.

62 Szabo Cl, Schutte M, Broeks A, et al. Are ATM mutations 7271T $\rightarrow G$ and IVS10-6T $\rightarrow$ G really high-risk breast cancer-susceptibility alleles? Cancer Res 2004:64:840-3.

63 Vorechovsky I, Luo L, Dyer MJ, et al. Clustering of missense mutations in the ataxia-telangiectasia gene in a sporadic T-cell leukaemia. Nat Genet 1997; 17:96-9.

64 Stilgenbaver S, Schaffner C, Litterst A, et al. Biallelic mutations in the ATM gene in T-prolymphocytic leukemia. Nat Med 1997;3:1155-9.

65 Stoppa-Lyonnet D, Soulier J, Lauge A, et al. Inactivation of the ATM gene in T-cell prolymphocytic leukemias. Blood 1998;91:3920-6.

66 Stankovic T, Weber P, Stewart G, et al. Inactivation of ataxia telangiectasia mutated gene in B-cell chronic lymphocytic leukaemia. Lancet 1999;353:26-9.

67 Bullrich F, Rasio D, Kitada S, et al. ATM mutations in B-cell chronic lymphocytic leukemia. Cancer Res 1999;59:24-7.

68 Schaffner C, Stilgenbauer S, Rappold GA, et al. Somatic ATM mutations indicate a pathogenic role of ATM in B-cell chronic lymphocytic leukemia. Blood 1999;94:748-53.

69 Schaffner C, Idler I, Stilgenbaver S, et al. Mantle cell lymphoma is characterized by inactivation of the ATM gene. Proc Natl Acad Sci U S A 2000;97:2773-8.

70 Saviozzi S, Saluto A, Taylor AM, et al. A late onset variant of ataxiatelangiectasia with a compound heterozygous genotype, A8030G/7481 insA. J Med Genet 2002;39:57-61.

71 Li A, Swift M. Mutations at the ataxia-telangiectasia locus and clinical phenotypes of A-T patients. Am J Med Genet 2000;92:170-7.

72 Tavani F, Zimmerman RA, Berry GT, et al. Ataxia-telangiectasia: the pattern of cerebellar atrophy on MRI. Neuroradiology 2003:45:315-19.

73 Barnes DE, Stamp G, Rosewell I, et al. Targeted disruption of the gene encoding DNA ligase IV leads to lethality in embryonic mice. Curr Biol 1998;8:1395-8.

74 Gao Y, Sun Y, Frank KM, et al. A critical role for DNA end-joining proteins in both lymphogenesis and neurogenesis. Cell 1998;95:891-902.

75 Herzog KH, Chong MJ, Kapsetaki M, et al. Requirement for Atm in ionizing radiation-induced cell death in the developing central nervous system. Science 1998;280:1089-91. 